\title{
مسؤولية المقاول العقدية عن فعل الغير
}

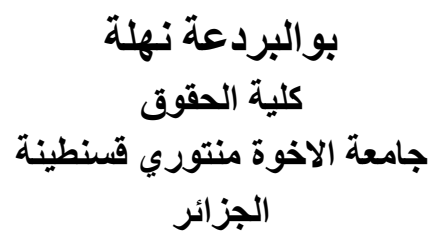

يعالج هذه المقال موضو ع المسؤولية العقدية للمقاول عن فعل الغير،حيث يجوز

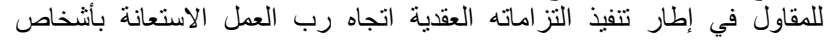

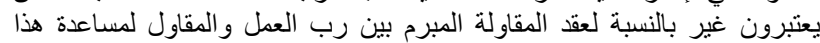

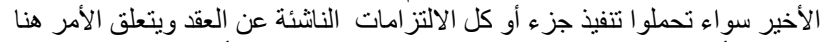

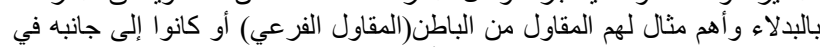

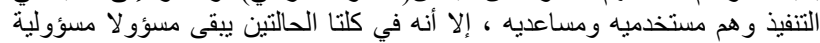

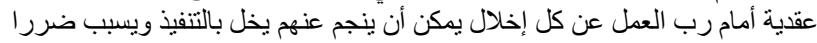

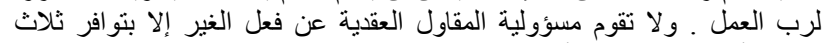

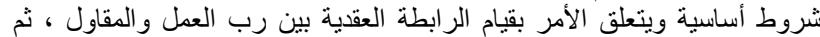

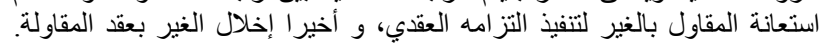

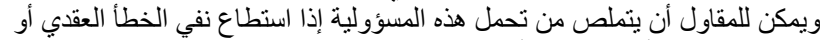

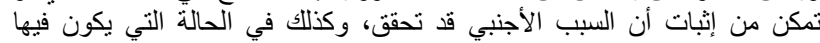
المقاول قد اشترط صر احة إعفاءه من هذه المسؤولية.

الكلمات المفتاحية : رب العمل، الغير(البدلاء،المساعدين) ،المسؤولية العقدية ،المقاول، المقاول من الباطن (الفرعي).

\section{Abstract:}

This study attempts to understand the contractual liability, trying to clarify the contractor's responsibilities, in fact, the contractor can hire other persons (substitutes) who are not part of the contract, in order to assist him in his work, like a subcontractor, who is an individual that accept to perform part or all of contractor's work or could be its employees (agents). In this regard, the contractor will be responsible to the employer for its obligations under the master contract, regardless of whether any breach is caused by the subcontractor or its employee, failing to perform its obligations under the contract.

While there are three conditions make the contractor responsible for substitutes'acts: The existence of the contract between the contractor and the employee, when the contractor uses a substitute to assist him in executing its contractual commitments, when the substitute violates the contract. However, the contractor may escape liability if it could deny the contractual mistake, or it could prove that an external factor caused this mistake, or it has explicitly stipulated to be exempt from such liability. 


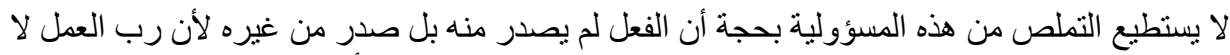

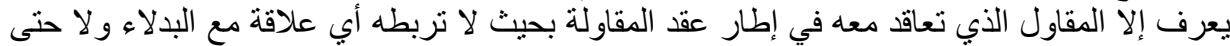

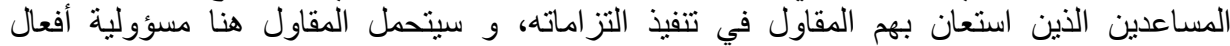

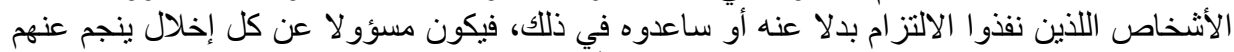

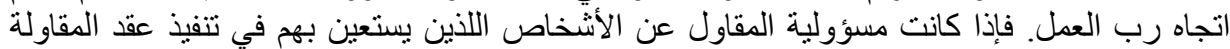

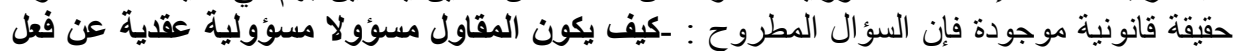

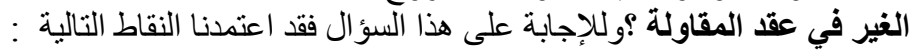

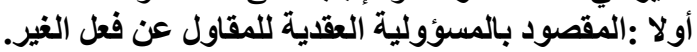

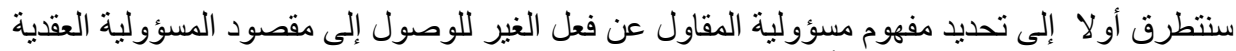

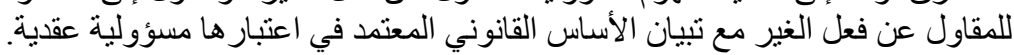

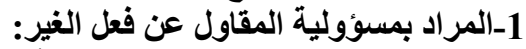

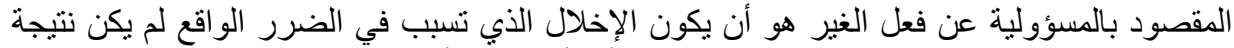

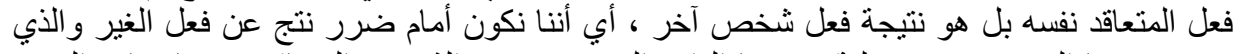

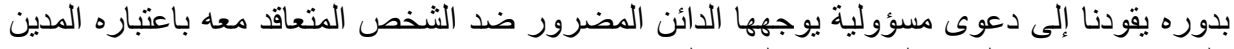

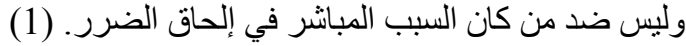

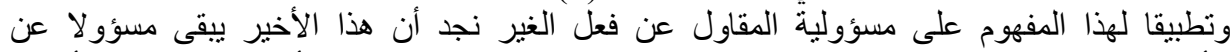

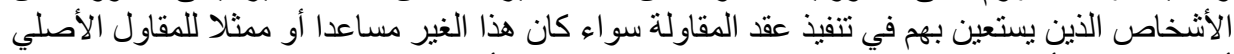

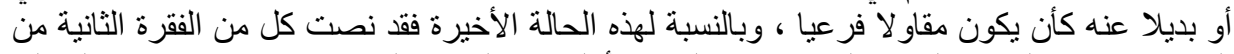

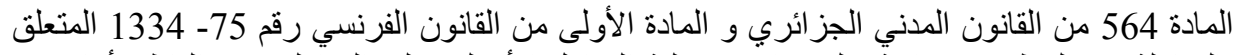

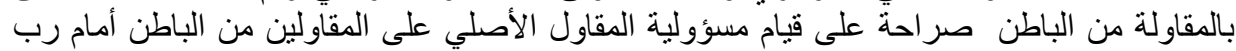
العمل

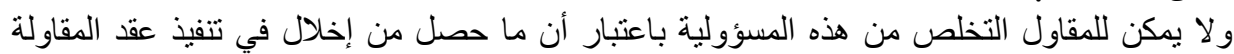

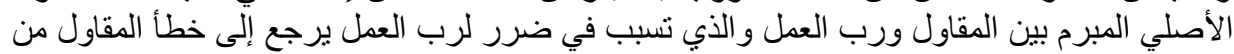

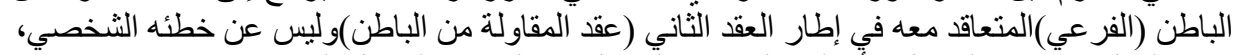

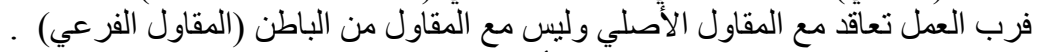

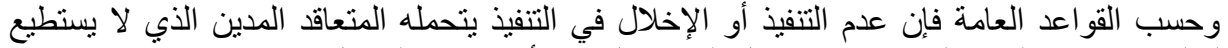

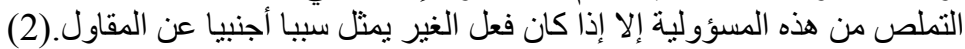

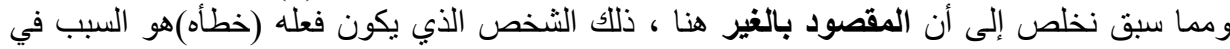

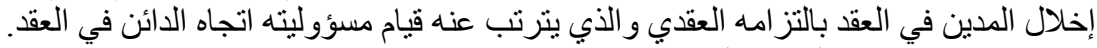

2-المقصود بالمسؤولية العقدية للمقاول عن فئل فعل الغير:

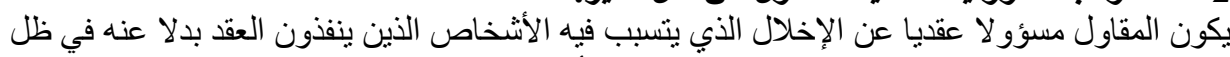

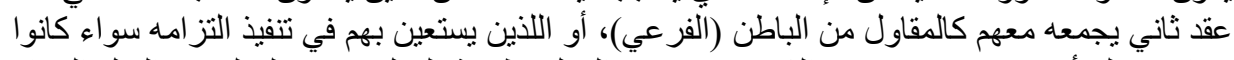

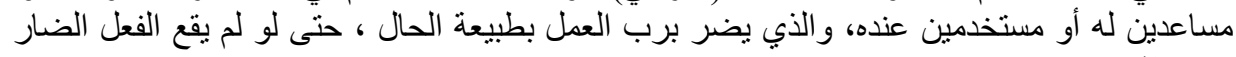

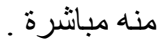

فرب العمل لا يعرف إلا المقاول المدين له أي المتعاقد معه في إطار عقد المقاولة فلا تربطه أي علاقة

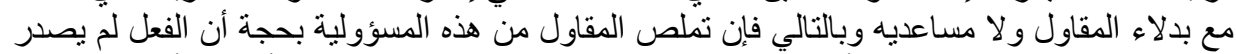

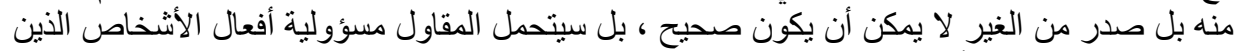

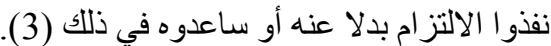

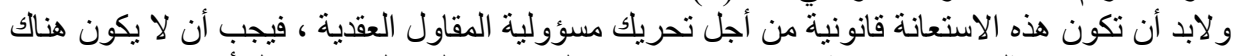

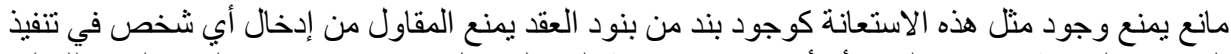

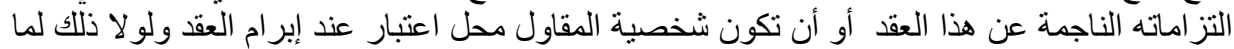
أبرم رب العمل معه هذا العقد كأن يكون مهندس ذأن كفاءة عالية كانت الدافع الوحيد في إبرام العقد العقد معه 
لأنه يتطلب كفاءة كبيرة لتنفيذهفالفقرة الأولى من المادة 564 من القانون الدني الجزائري كانت

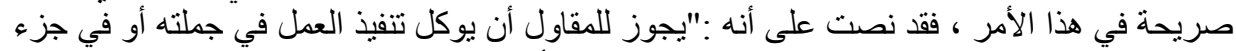

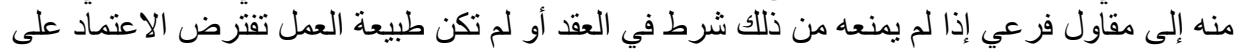

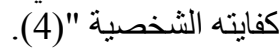

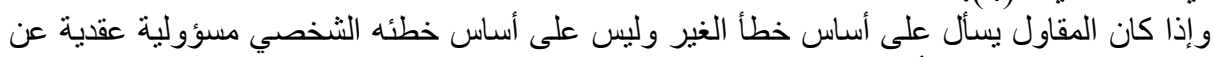
فعل الغير هنا ـ فما هو الأساس القانوني المعتمد في اعتبار هذه المسؤولية عقدية وليست تقصيرية الئي

\section{3-الأساس القانوني المعتمد في اعتبار مسؤولية المقاول عقدية عن فعل الغير:}

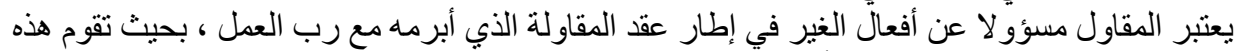

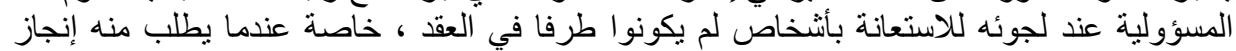

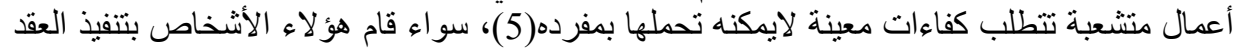

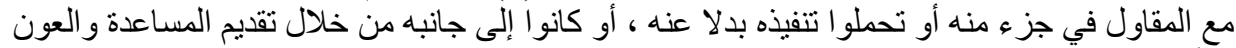

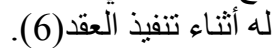

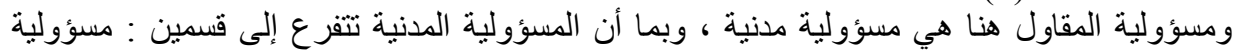

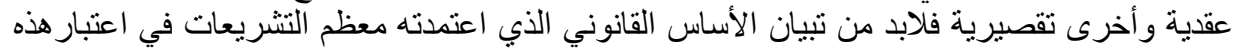
المسؤولية عقدية.

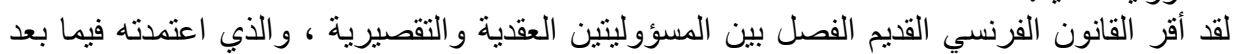

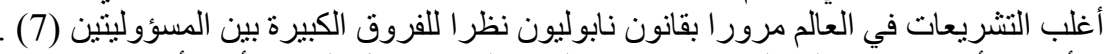

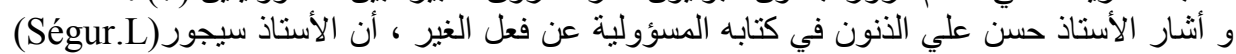

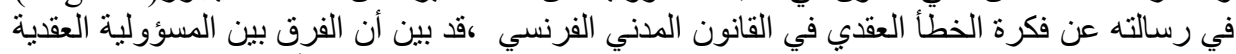

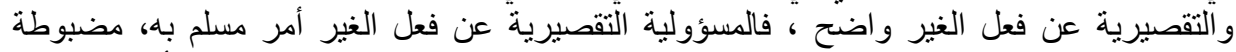

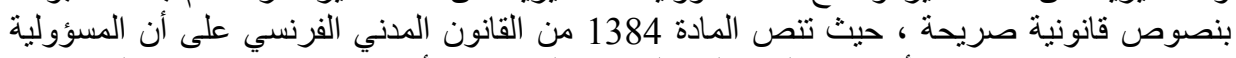

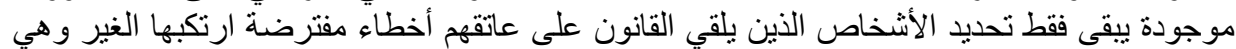

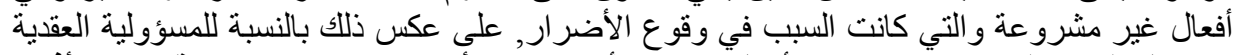

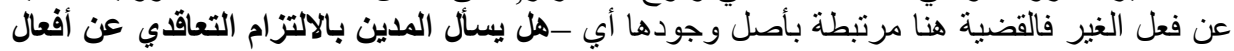
الغير الذين استعان بهم في تنفيذ التزامه أو أشركهم في ذلك و كانوانوا السبب في في عدم تنفيذّ أو أخلوا

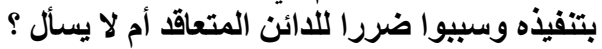

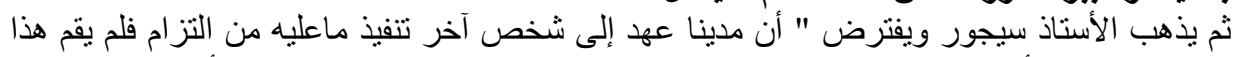

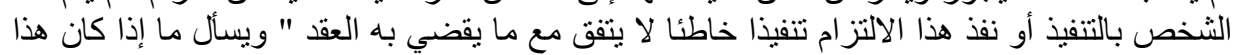

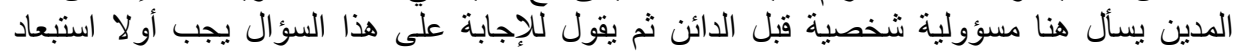

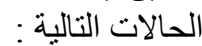
ـالحالة التي يلقي فيها القانون نتائج القوة القاهرة أو الحادث الفجائي على عاتق الددين. ـالحالة التي يضمن فيها الدين صنين صر احة فعل الغير أو خطئه .

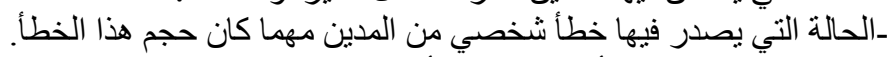

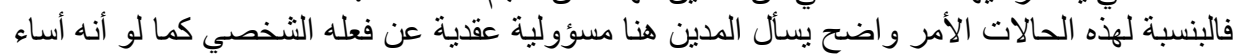

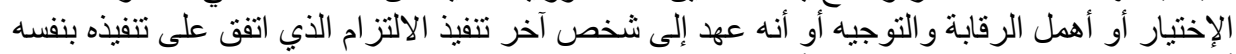

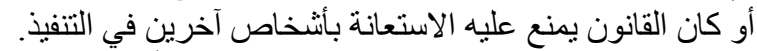

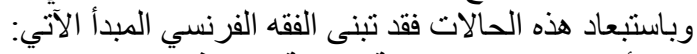

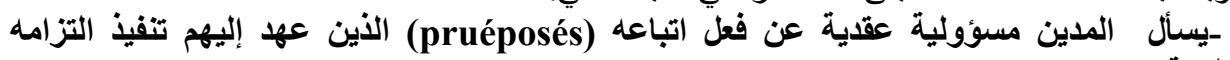

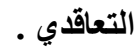

كما أن "القضاء الفرنسي تدخل في تحديد الأشخاص الذين بسأل المدين عن أفعالهم مسؤولية عقدية

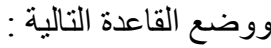


لا تقتصر المسؤولية العقدية عن أفعال أتباعه ووكلائه فحسب بل تمتد لتشثل كل أولئك الأشخاص

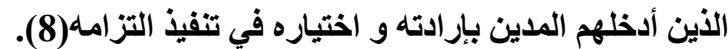

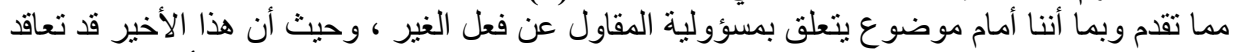

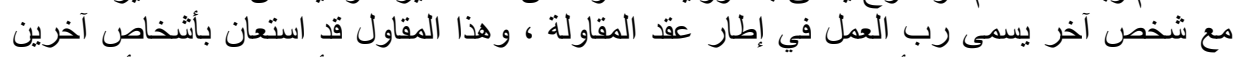

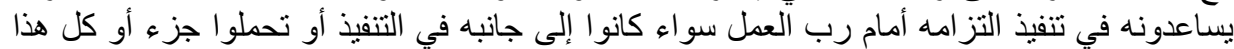

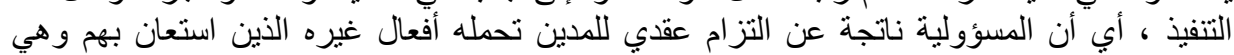

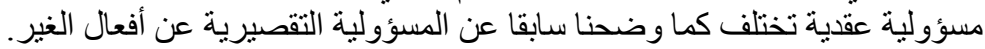

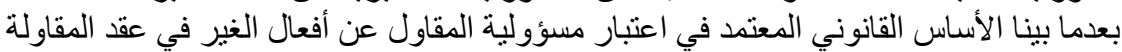

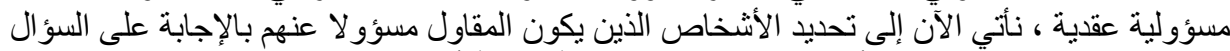

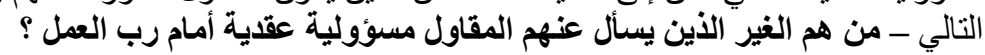

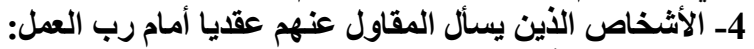

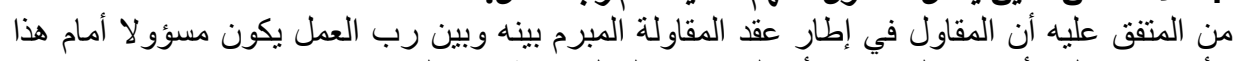

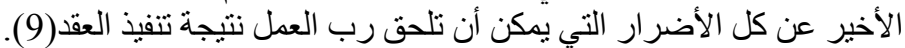

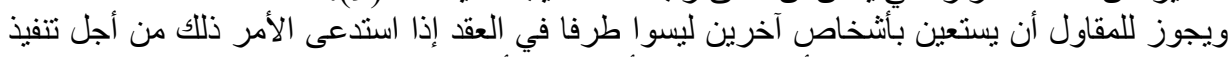

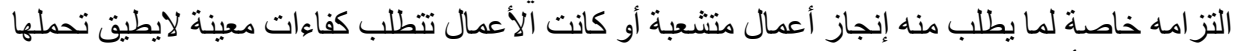

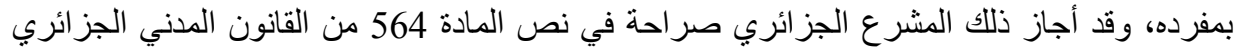

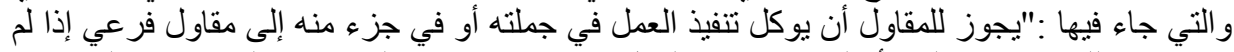

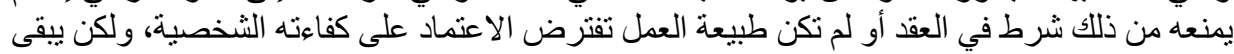

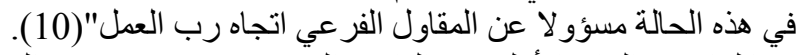

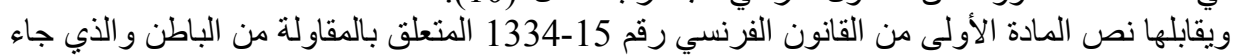

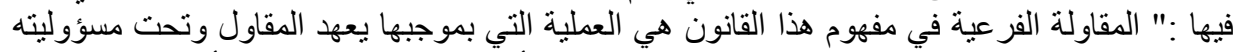

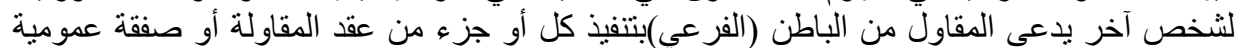

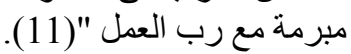

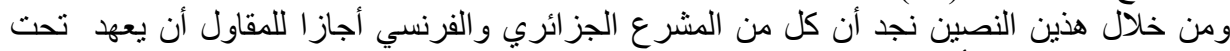

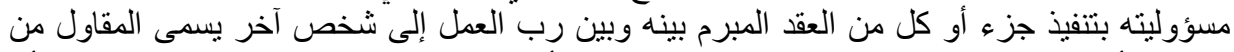

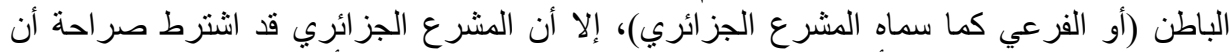

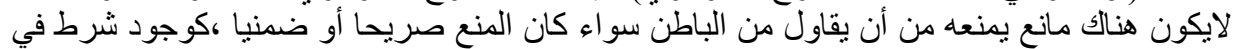

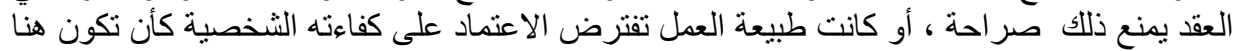
شخصية المقاول محل اعتبار في إبر ام العقد(مثلا في الحالة التي يكون فيها المقاول المقاول مهندس ذا كفاءة أبرم معهد المقاول العقد بسبب احترل افيتهن).

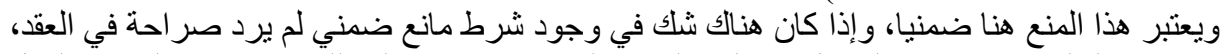

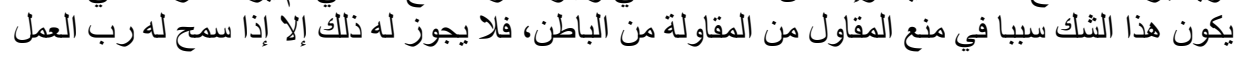

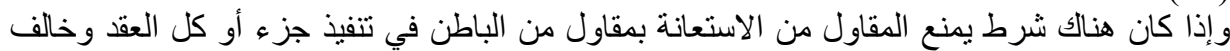

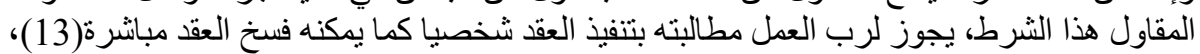

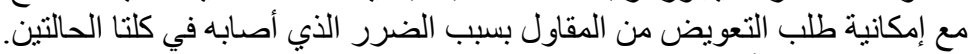

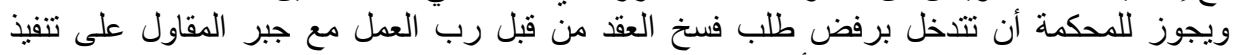

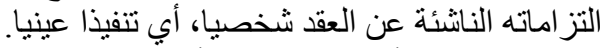

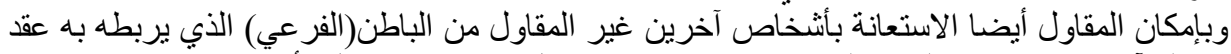

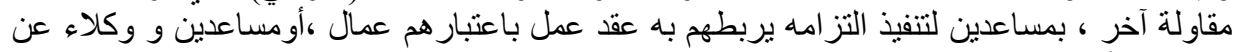

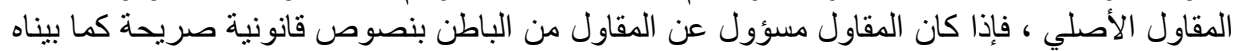
سابقا ،فإن هذه المسؤولية لا تقتصر على المقاول من الباطن فقط بل تمند إلى كل الأشخاص الذية الذين يعتمد 
عليهم المقاول في تتفيذ التزامه اتجاه رب العمل بما فيهم المساعدين ، الأعوان أوحتى ممثلين

مما تقام يمكن حصر الغير الذي بسأل عنه المقاول عن الإخلال الناجم في تتفيذ عقد الدقاولة والذي الإني

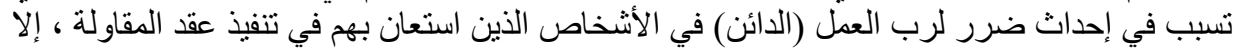

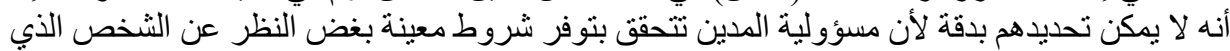

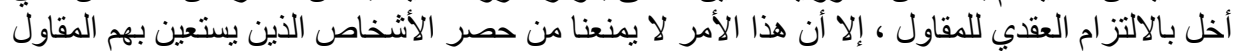
في تنفيذ التزامه ضمن مجمو عتين هما :

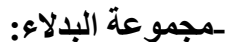

ويتعلق الأمر هنا بالأشخاص الذين يكلفهم المقاول الددين بتنفيذ كل العقد أو جزء مناء البه تنفيذا مستقلا

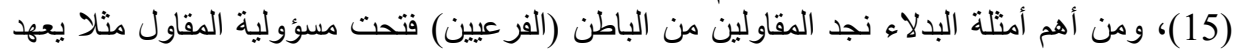

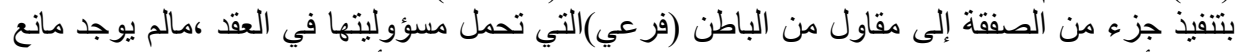

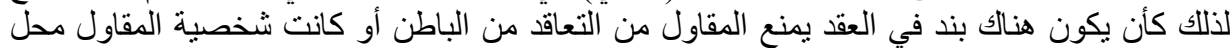

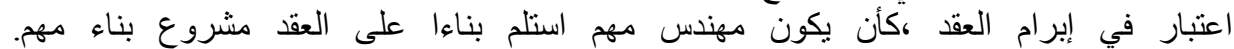

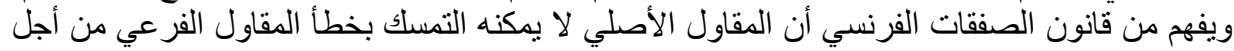

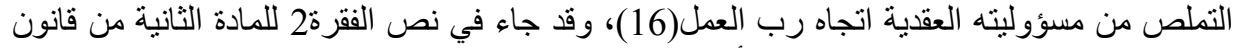

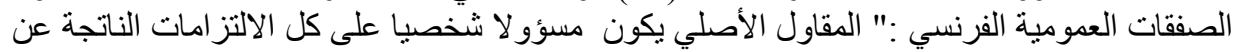

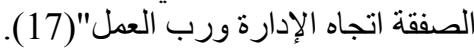

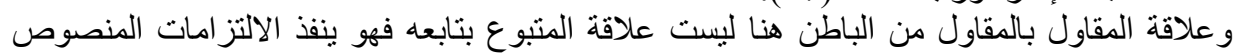

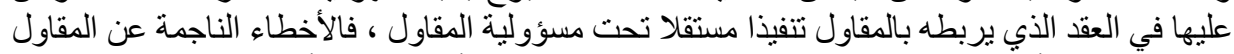

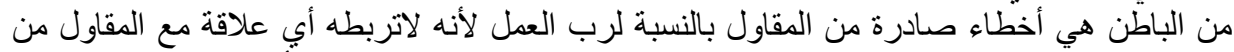

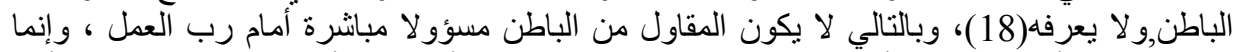

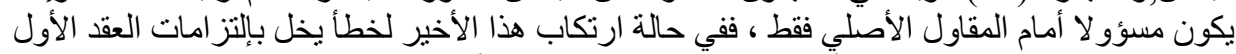

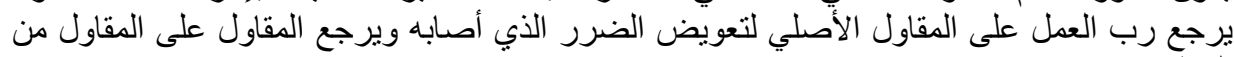

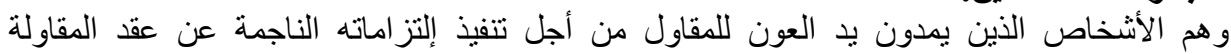

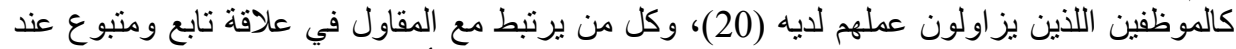

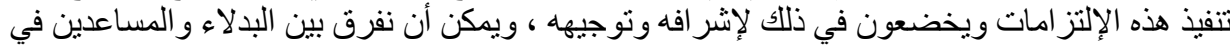

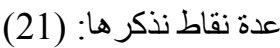

ـالمساعدين تابعين للمقاول في تنفيذ العقد أما البدلاء يكونو المستقلين عن المقاولين في تتفيذ العقد.

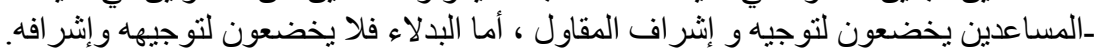

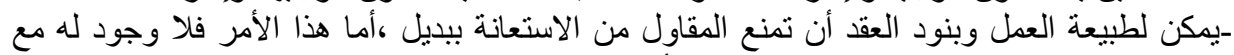

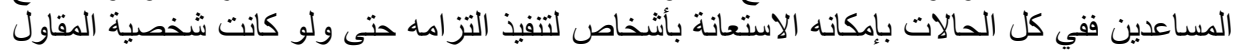

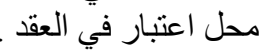
ـالمساعدين يساعدون المقاول فقط ،أما البدلاء فيقومون بتنفيذ جزء من العمل وبالتالي عمهم له أهية كبيرة.

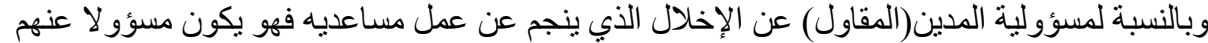

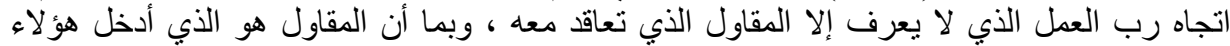

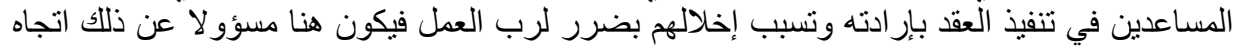


ثانيا:شروط قيام مسؤولية المقاول العقدية عن فعل الغير.

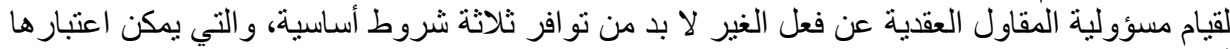

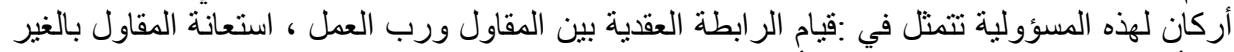

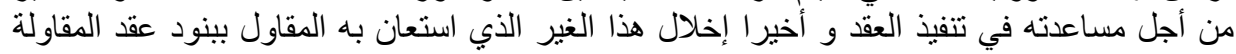

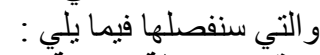

1 1إيتام الرابطة العقدية بين المقاول ورب العمل:

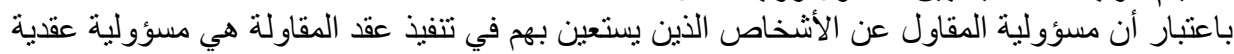

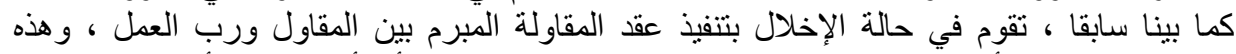

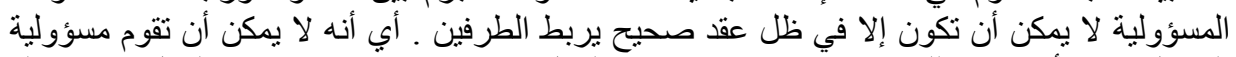

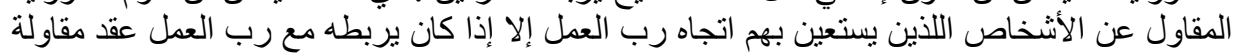

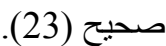

وعقد المقاولة وفقا لنص المادة 549 من القانون المدني الجزائري هو "عقد يتعهد بمقتضاه أحد

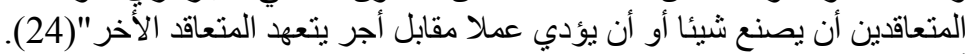

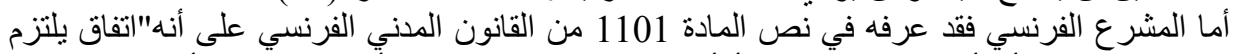

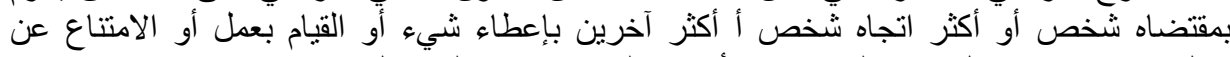

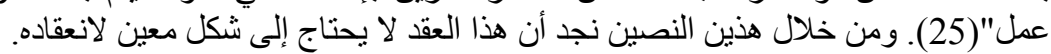

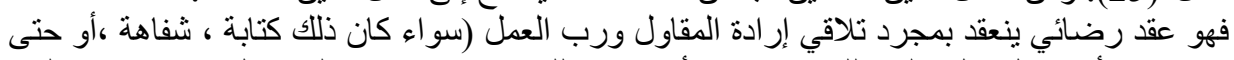

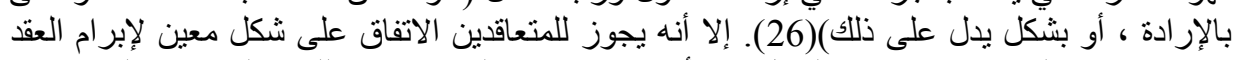

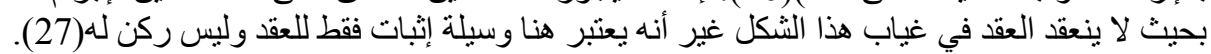

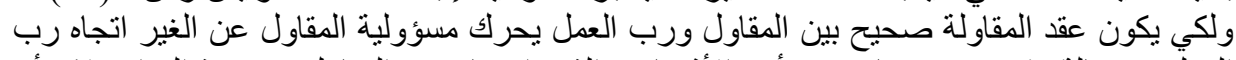

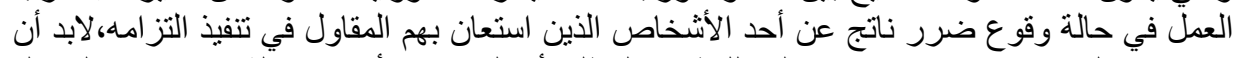

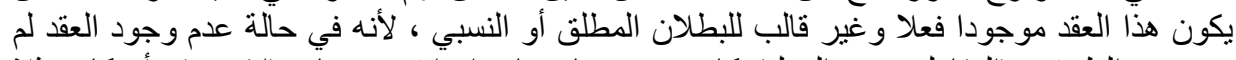

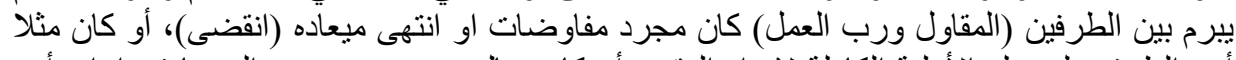

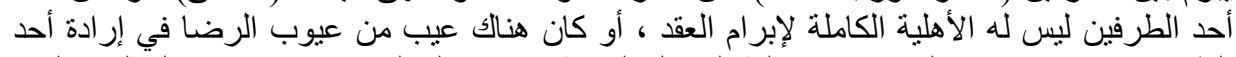

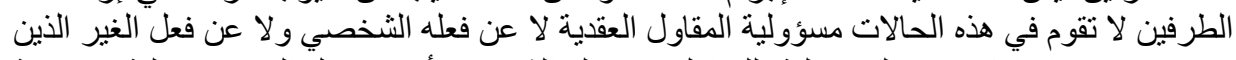

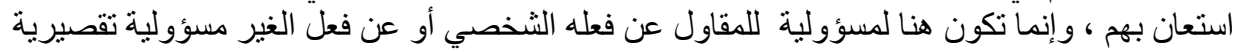

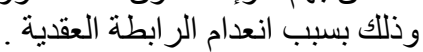

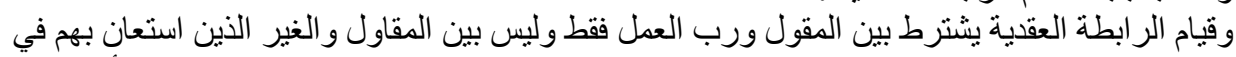

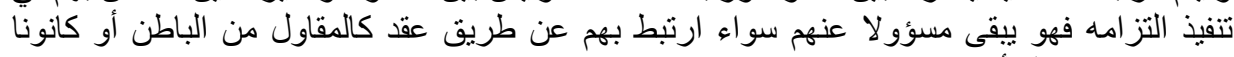

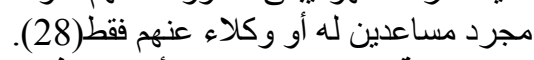

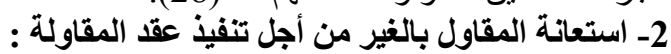

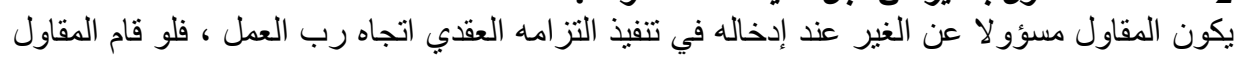

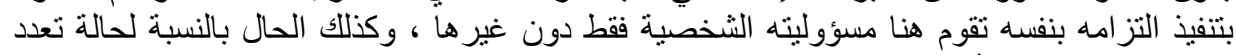

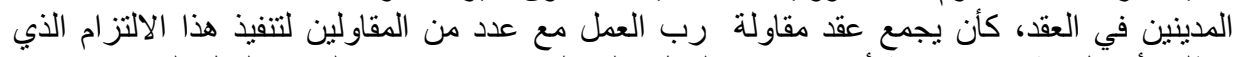

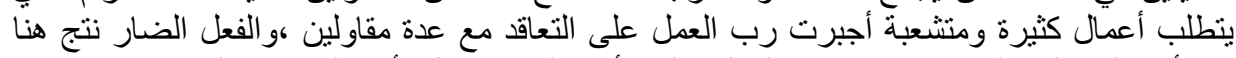

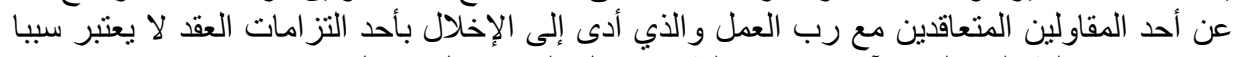

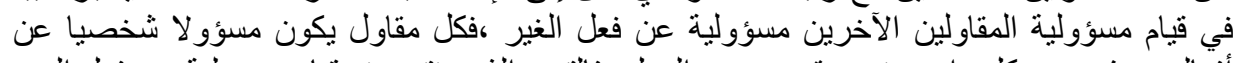

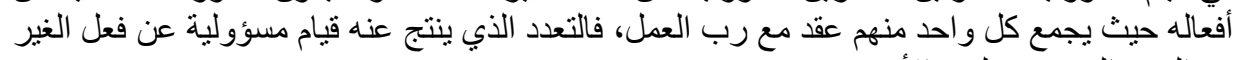
هو التعدد العمودي وليس الأفقي.

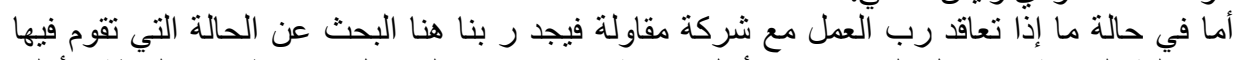

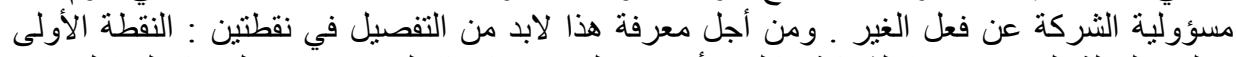

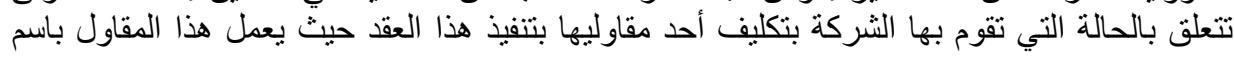




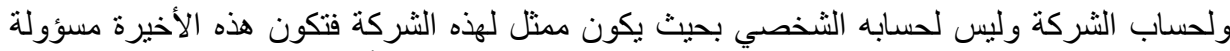

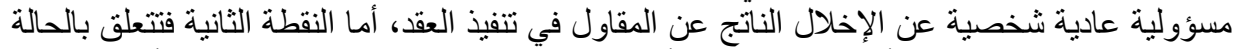

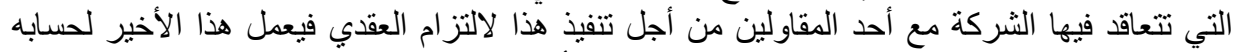

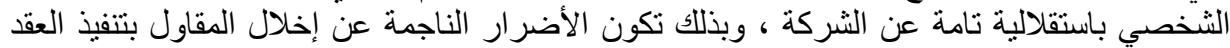

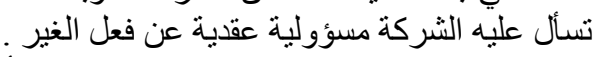
ولكي تقوم هذه المسؤولية عن فعل الغير يجنب أنغل أن نكون استعانة هذا المقاول بالغير في إطار قانوني

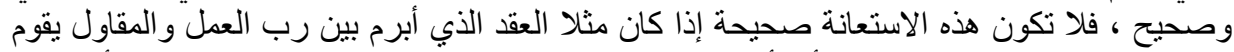

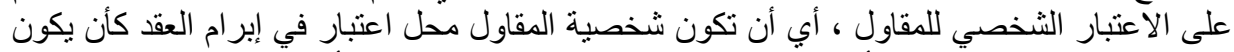

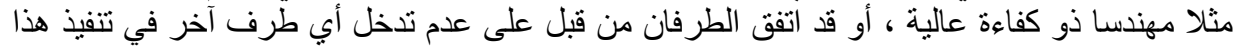

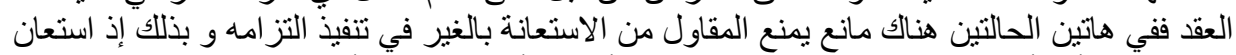

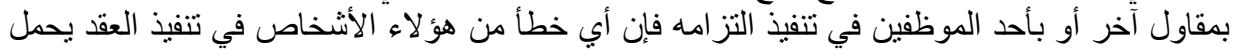

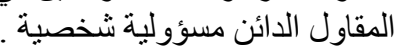
أما إذا أجاز كل من القانون وبنود العقد ذلك إلا أن الخطأ كان في اختيار المقاول المدين للأثخاص الذين

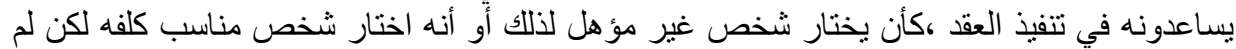

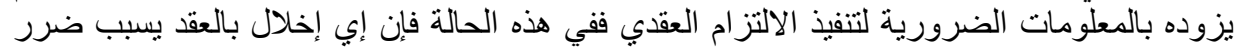

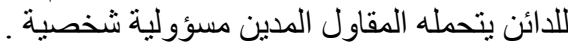

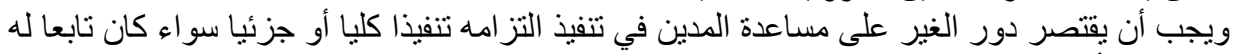

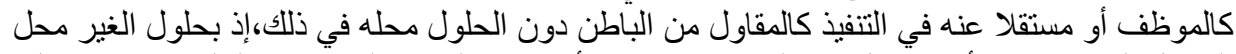

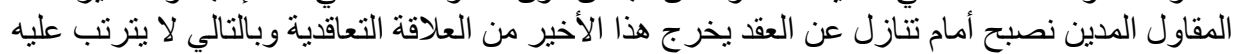

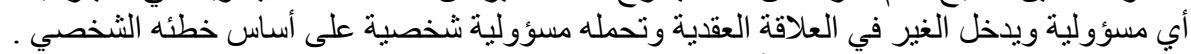
و وعلى العموم فإن تدخل الغير يمكنه أن يكون: -

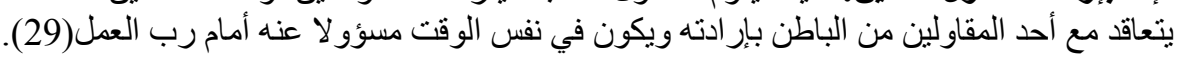

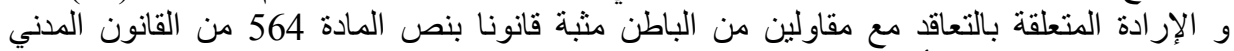

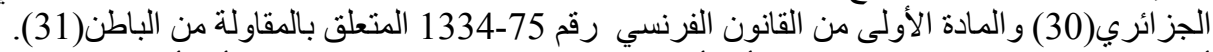

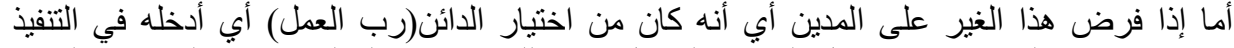

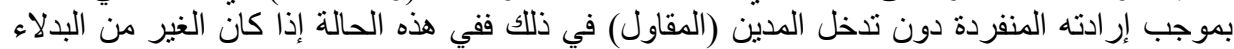

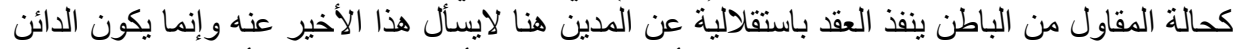

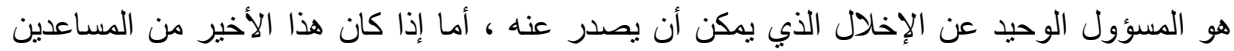

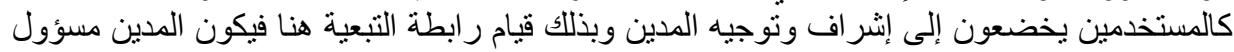

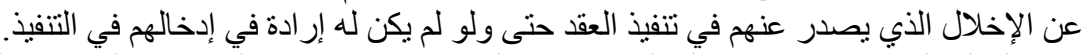

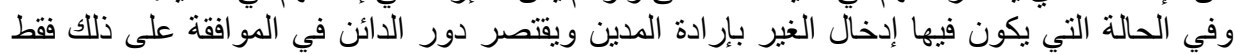

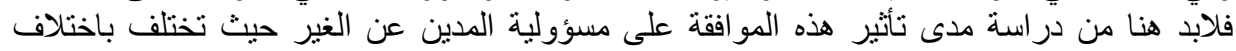

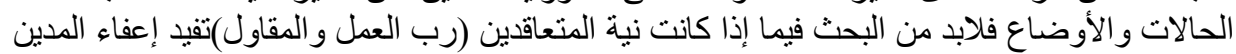

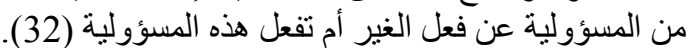

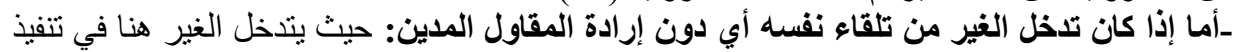

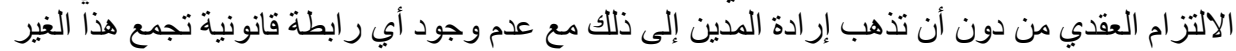

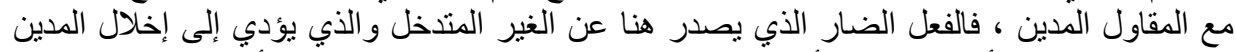

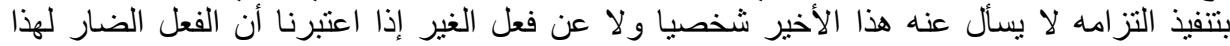

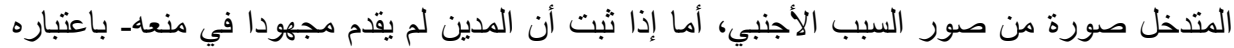

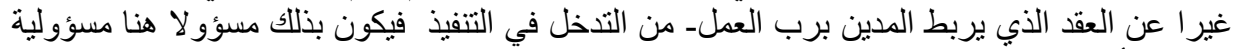
شخصية أمام رب العمل وليس مسؤو لا عن فعل الغير (33). 
3-إخلال الغير بعقد المقاولة:

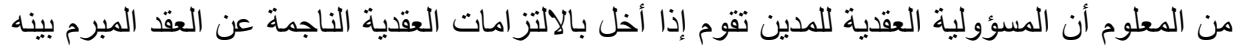

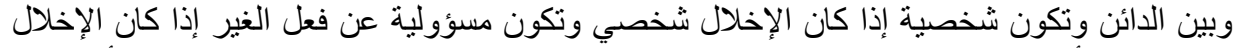

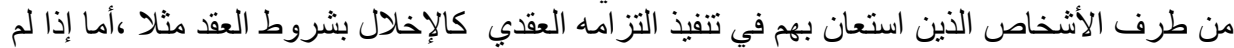

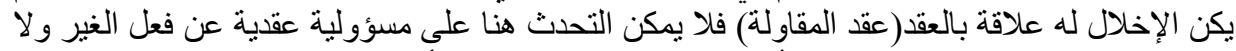

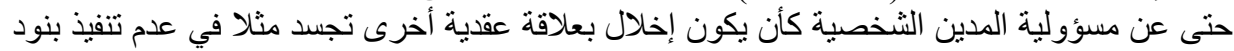

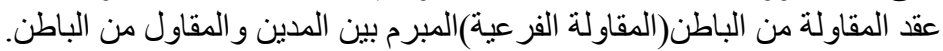

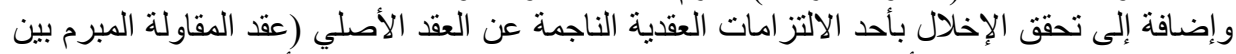

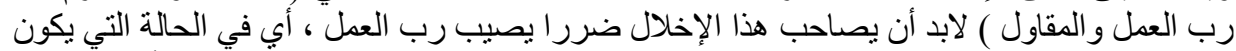

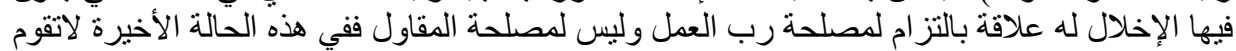

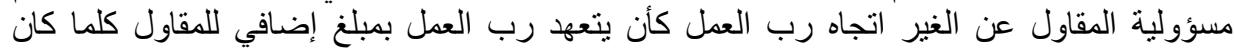

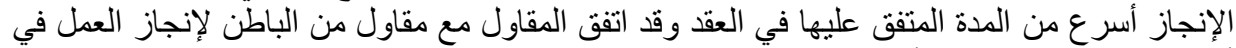

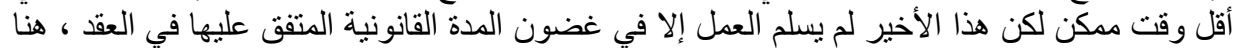

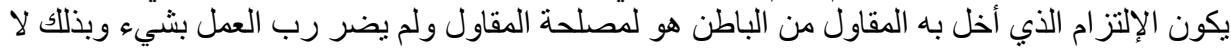

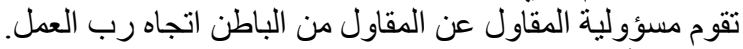

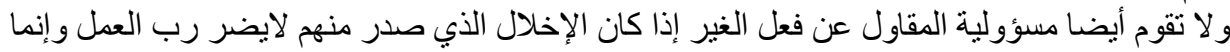

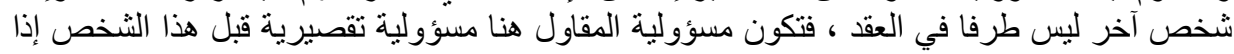
توافرت شروطها.

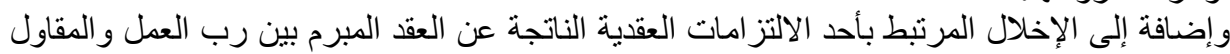

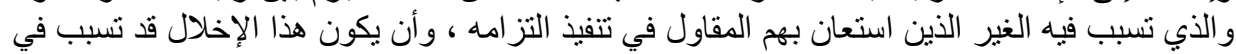

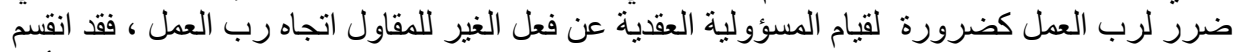

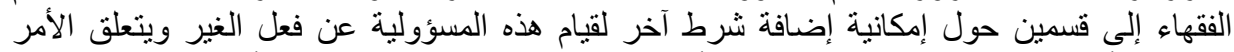

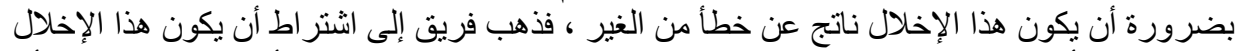

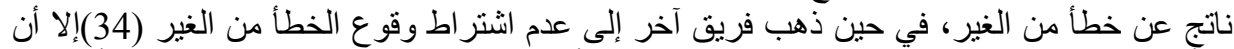

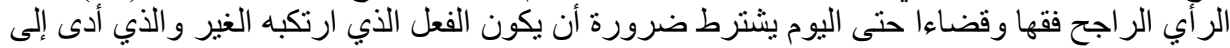

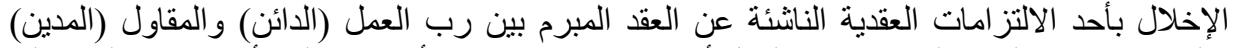

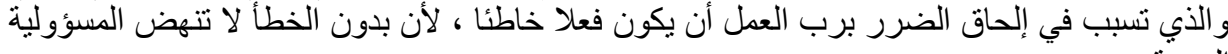

كقاعدة عامة.)(35) - كاية

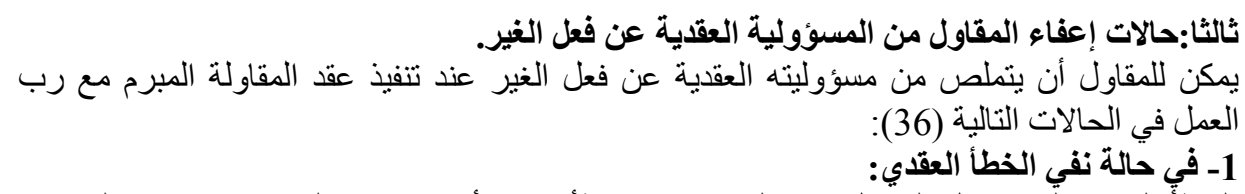
الخطاً العقدي الذّي يعمل المقاول هنا على نفيه هو خطأ بدلائه أو مساعديه الذين قاموا بتنفيذ التزاماته

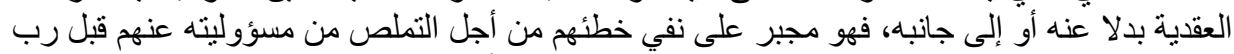

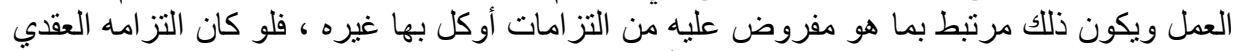

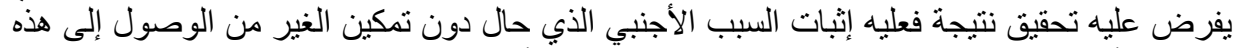

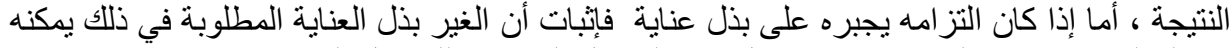
من التخلص من مسؤوليته ويمكن استعمال كافة الوسائل الممنوحة للتوصن التهل إلى إثباتاته. 


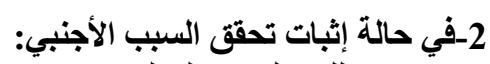

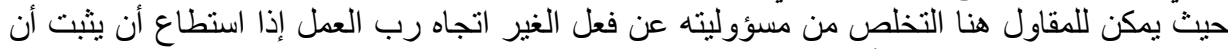

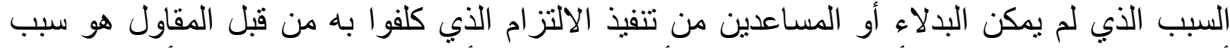

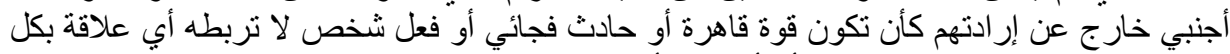

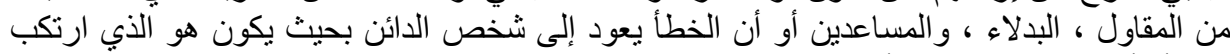

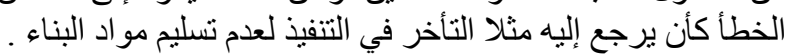

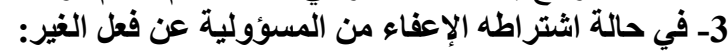

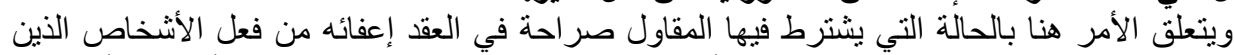

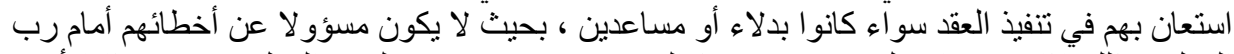

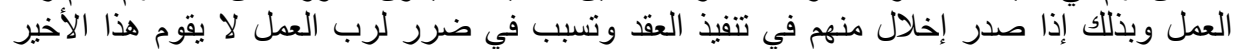

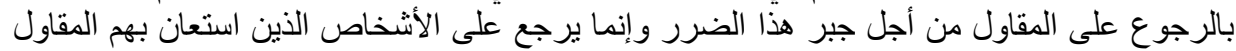

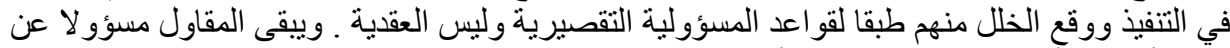

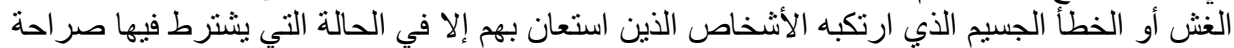
في العقد عدم مسؤوليته عنهم حتى في حالة استعمالهم الغش أو ارتكابن الإنهم لخطأ جسيم عند التتفيذ.

خاتمة

بعد در استتا لموضوع مسؤولية المقاول العقدية عن فعل الغير توصلنا إلى النتائج التالية:

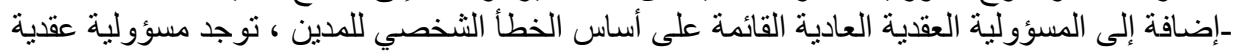

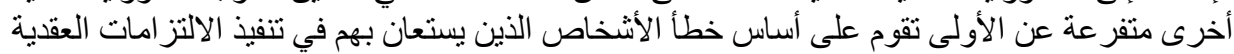

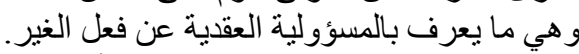

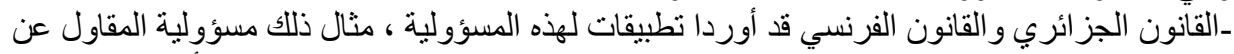

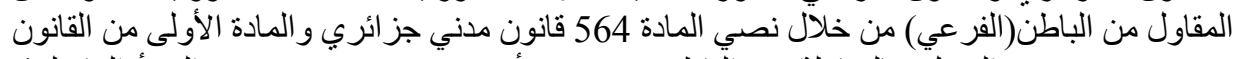

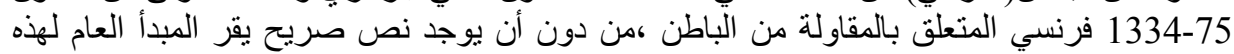
الأمسؤولية في كلاهما. ـا لا يجوز للمقاول الاستعانة بالغير من أجل تنفيذ التزاماته إذا كان هنالك بند في العقد يمنع ذلك، أو كانت

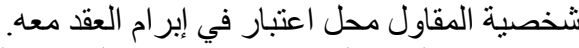

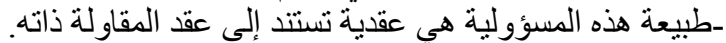

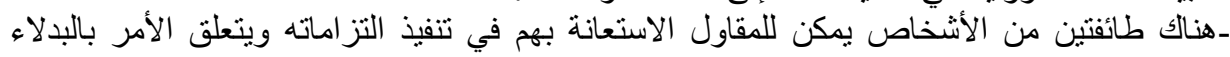
و المساعدين. - وضع فقهاء القانون المدني ثلاث شروط لقيام هذه المسؤولية وهي على التو الي: قيام الرابطة العقدية

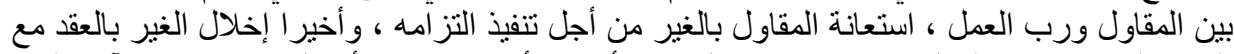

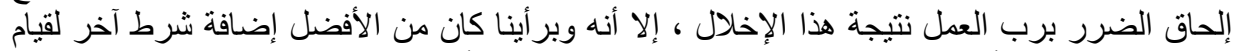

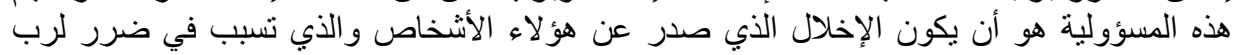

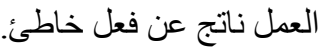

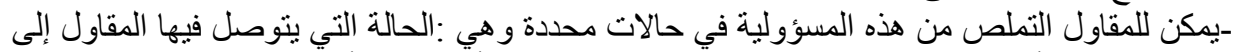

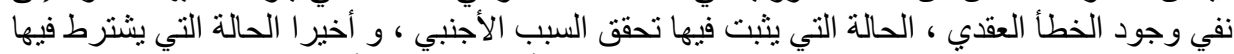

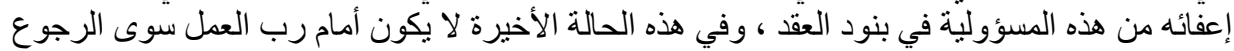

على الثخص الذي استعان به المقاول في التنفيذ ووقع منه الإخلال طبقا لقو اعد المسؤولية التقصيرية. 


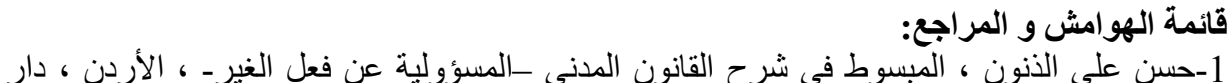

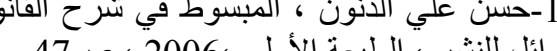

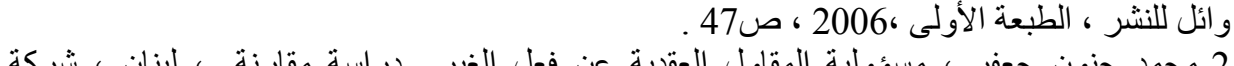

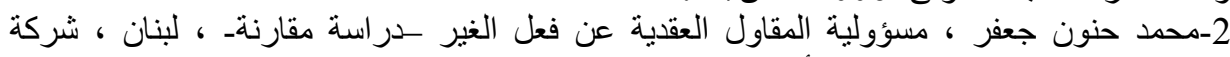
المؤسسة الحديثة للكتاب ، الطبعة الأولى ، 2011 ، ص ص 143 ، 129 .

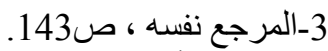

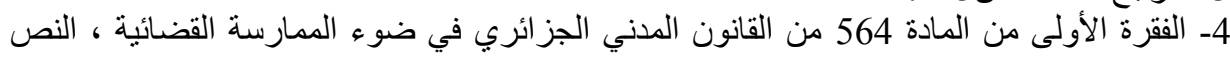

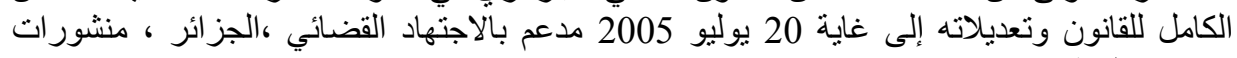

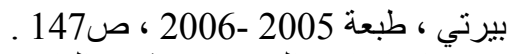

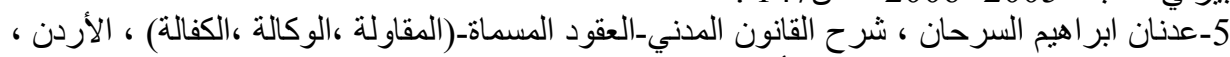

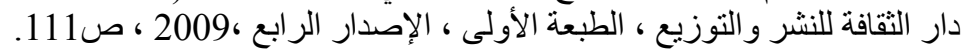

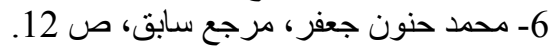

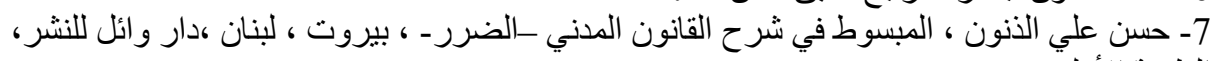

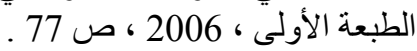

8-حسن علي الذنون ، المبسوط في شرح القانون المدني ، المسؤولية عن فعل الغير ، مرجع سابق ،

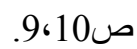

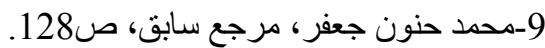
10 - المادة 564 من القانون المدني الجز ائري، مرجع سابق سابق. 11 - article 1 de la loi n75-1334, du 31 décembre 1975, relative à la soustraitance, J.O du 03 janvier 1976, p148.

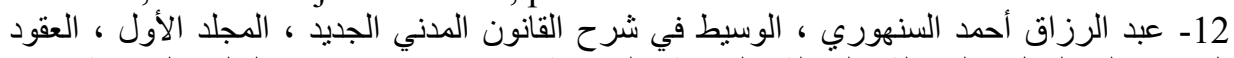

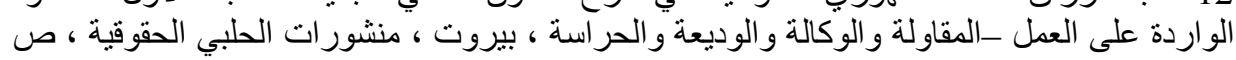
.209،210

13-ابراهيم سيد احمد ، العقود الواردة على العمل-عقد الدقاولة فقها وقضاءاء- ،الإسكندرية، منشأة

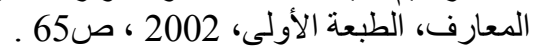

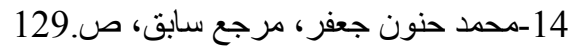

15-حسن علي الذنون ،المبسوط في شرح القانون المدني ، المسؤولية عن فعل الغير ، مرجع سابق ، ص ص

16-Franck Moderne, la sous-traitance des marchés publics, paris, éditions DALLOZ, 1995, p203.

17- ibid.

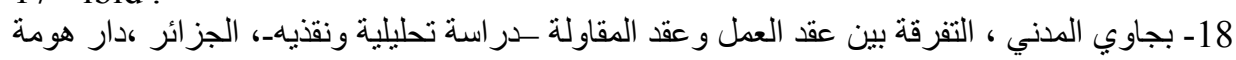

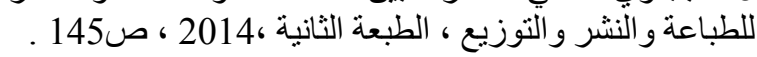

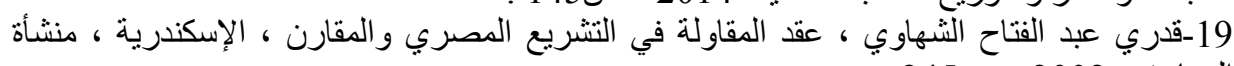

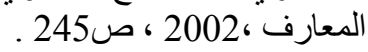

20- حسن علي الذنون ، المبسوط في شرح القانون المدني ، المسؤولية عن فعل الغير ، مرجع سابق ،

21-21-محمد حنون جعفر ، مرجع سابق، ص167-165-167.

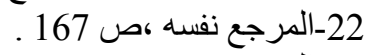

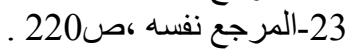

24-المادة 23 549 من القانون المدني الجزائري، مرجع سابق.

25-ابر اهيم سيد احمد ، مرجع سابق ، ص. 949 
26-فتيحة قرة ، أحكام عقد المقاولة ، الإسكندرية ، منشأة المعارف، طبعة 1987 ، ص.18

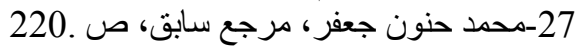

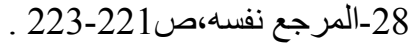

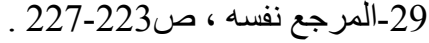

30 - المادة 564 من القانون المدني الجز ائري، مرجع سابق.

cit..31- Article 1, de la loi n 75-1334, op

32-محمد حنون جعفر ، مرجع سابق، ص.227

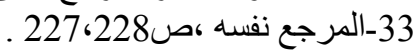

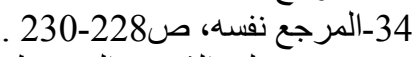

35- حسن علي الذنون ،المبسوط في شرح القانون المدني ، المسؤولية عن فعل الغير ،مرجع سابق ،

36-محمد حنون جعفر، مرجع سابق، ص241-244. 